\title{
The functional-morphological adaptive strategy of digestive organs of decapodiform cephalopods
}

\author{
Ayano OMURA ${ }^{1,2) *}$ and Hideki $\mathrm{ENDO}^{2)}$ \\ ${ }^{1)}$ Graduate School of Agricultural and Life Sciences, The University Museum, The University of Tokyo, 7-3-1 Hongo, Bunkyo-ku, Tokyo \\ 113-0033, Japan \\ ${ }^{2)}$ The University Museum, The University of Tokyo, 7-3-1 Hongo, Bunkyo-ku, Tokyo 113-0033, Japan
}

(Received 27 March 2015/Accepted 4 August 2015/Published online in J-STAGE 11 September 2015)

ABSTRACT. The digestive organs in decapodiform cephalopod species morphologically vary by individual lifestyle. We examined the following six species of adult decapodiformes cephalopods representing different habitats: Todarodes pacificus, Loligo bleekeri, Loligo edulis, Watasenia scintillans (pelagic), Sepia lycidas and Euprymna morsei (benthic). L. bleekeri and L. edulis possess a bursiform cecal sac connected to the cecum. Pelagic species have a single digestive gland smaller than in benthic species. T. pacificus has an oval digestive gland larger than that of L. bleekeri and L. edulis, which possess withered-looking and smaller digestive glands. In contrast, the digestive glands in benthic species are paired. S. lycidas and E. morsei have well-developed and larger digestive glands than those of the pelagic species. Well-developed digestive duct appendages are found in benthic species. In qualification of the mass of digestive organs, pelagic species have smaller stomachs, digestive glands and digestive ducts' appendages than benthic species. Because pelagic species need to swim, they may possess smaller stomachs and larger cecums for more rapid digestion. A smaller digestive gland may have the advantage of reducing the body weight in pelagic species for rapid swimming. In contrast, since benthic species require a longer time for digestion than pelagic species, they compact more food in their stomachs and absorb nutrients via more organs, such as the digestive grand and digestive duct appendages, in addition to cecum.

KEY WORDS: cecum, decapodiform, digestive organ, locomotion, stomach

doi: 10.1292/jvms.15-0185; J. Vet. Med. Sci. 78(1): 43-47, 2016

Decapodiform cephalopods can be found worldwide, between the tides, in the deep ocean and in surface water [14]. For example, they include plankton, neuston, passive flaters, active swimmers and simply neritic or oceanic species [18]. Their habitats differ according to species with the two main groups being pelagic species and benthic species. In the stomach content of coastal and benthic cephalopods, shrimps, prawns and crabs are most commonly found crustaceans, whereas oceanic cephalopods eat pelagic crustaceans more commonly [4]. Fish are an important food source for adult cuttlefish, a benthic species [9]. Cuttlefish are noted for their wide-ranging diets [13]. The diets of the mature cuttlefish include large crabs and fishes [17].

Hanlon and Messenger [14] reported that many cephalopods are generally opportunistic feeders, consuming whatever is available. In general, the morphology of the digestive organs may be affected by differences in food. In this case, since decapodiform cephalopods eat fish and crustaceans, it seems likely that their digestive organs would be similar among species. However, Mangold and Young reported differences in the morphologies of the digestive organs among

\footnotetext{
*Correspondence to: Omura, A., Graduate School of Agricultural and Life Sciences, The University Museum, The University of Tokyo, 7-3-1 Hongo, Bunkyo-ku, Tokyo 113-0033, Japan. e-mail: ayanodesuyoroshiku@yahoo.co.jp C2016 The Japanese Society of Veterinary Science

This is an open-access article distributed under the terms of the Creative Commons Attribution Non-Commercial No Derivatives (by-nc-nd) License $<$ http://creativecommons.org/licenses/by-nc-nd/3.0/>.
}

cephalopods [16]. Digestion takes longer in benthic species than in pelagic species [4], suggesting that the shape of the digestive organs may be strongly related to variations in habitat and digestive requirements in addition to food.

In cephalopods, food is broken down in the stomach [16], and the digestive fluid enters the cecum [4]. In Sepia, the digestive fluid is then conducted through the digestive duct's appendages and enters the digestive gland [4]. In Loligo, food does not seem to go to the digestive gland [2]. Ultimately, food is excreted through the intestine [4].

The cecum has been considered the main absorptive organ $[1,3,10]$. The cecum produces enzymes, absorbs nutrients and eliminates indigestible particles, and nutrients are stored in the cecal sac [16]. In Loligo, the absorptive precess is handled by their large cecal sac and intestine [2]. In contrast, in Sepia, the intestine does not seem to play a noticeable role in digestive absorption [4]. The digestive gland accumulates dietary lipids $[5,8,15,16]$ and has the potential to excrete lipids $[11,16,19,20]$. Although the functions of the digestive duct's appendages have yet to be defined, their absorptive function was shown in Sepia [3]. Cephalopod digestive organs have been described by Boucaud-Camou and Boucher-Rodoni [4], Mangold and Young [16] and Garri and Edith Ré [12]. In the oegopsid squid, Voss and Voss [21] reported the relative sizes of cecum and stomach.

Despite these studies, the relationships between the morphology of digestive organs and digestion time have not been quantified. Although the relationships between the morphology of the intestine and the mode of food processing have been reported with respect to the length and structure 
of the intestine [16], other digestive organs have not been investigated. To clarify the adaptive strategy regarding the shape of digestive organs, a comparative anatomical study has been needed.

Thus, in the current study, we investigated morphological variations of the digestive organs in decapodiform cephalopods by examining and weighing each organ. This study aimed to quantify the morphological disparities in the digestive organs in decapodiform cephalopods of different ecotypes and construct a theory regarding the adaptive strategy of digestive organs in different ecotypes.

\section{MATERIALS AND METHODS}

Specimens: Six species of decapodiform cephalopods representing 5 families and 2 different lifestyles (pelagic and benthic) were used in this study (Table 1). Pelagic species included Todarodes pacificus $(\mathrm{n}=4)$, Loligo bleekeri $(\mathrm{n}=4)$, Loligo edulis $(\mathrm{n}=4)$ and Watasenia scintillans $(\mathrm{n}=4)$, all of which have elongated bodies and swim actively. Loliginids are epipelagic active swimmers. W. scintillans usually lives in the mesopelagic zone. Benthic species included Sepia lycidas $(\mathrm{n}=4)$ and Euprymna morsei $(\mathrm{n}=4)$. S. lycidas has a flattened body with a cuttlebone, and E. morsei possesses a pouched body with a round fin. E. morsei is a sand burrower. Each specimen was fixed in a straight body position using $10 \%$ formalin and preserved in $70 \%$ ethanol solution.

Observation and quantification of digestive organs: Observation and measurement were conducted at the University Museum, the University of Tokyo, in July 2014. Specimens were dissected, and digestive organs were exenterated. All observations were performed from each specimen's ventral side. Images of the digestive organs were obtained using a single-lens reflex camera.

To determine organ weight, the digestive organs were dissected from all 6 specimens using tweezers. The following digestive organs were examined: stomach, cecum, digestive gland and digestive duct's appendages. The contents of stomach were removed by dissection to obtain the stomach weight without the contents. Each digestive organ was weighed using an electronic balance (Shimadzu AUW220D or Shimadzu UX420H, Shimadzu Corporation, Kyoto, Japan). The percentage ratio of each organ's weight to total body weight was calculated for the 6 species based on their respective body masses. Statistical tests were conducted with the JMP Pro 9 statistical analysis software (SAS Institute Inc., Cary, NC, U.S.A.). The Holm method was used to compare the weight ratios for the digestive organs from the 6 species included in this study.

\section{RESULTS}

Observations: The images of the digestive organs of 6 species of decapodiform cephalopods are shown in Fig. 1. The shape of the pathway of the digestive duct was similar among all 6 species. The esophagus lay on the dorsal side of the digestive gland and opened into the stomach. The stomach was situated together with the cecum. The digestive duct appendages were connected between the cecum and digestive gland. The intes-
Table 1. Specimens used in this study

\begin{tabular}{|c|c|c|c|}
\hline Species & Habitat & $\mathrm{ML}^{*}(\mathrm{~cm})$ & Body weight (g) \\
\hline \multirow[t]{4}{*}{ Todarodes pacificus } & Pelagic & 22.8 & 289.2 \\
\hline & & 22.1 & 231.8 \\
\hline & & 20.6 & 195.3 \\
\hline & & 19.3 & 145.8 \\
\hline \multirow[t]{4}{*}{ Loligo bleekeri } & Pelagic & 18.1 & 210.1 \\
\hline & & 17.3 & 184.3 \\
\hline & & 16.5 & 156.1 \\
\hline & & 16.6 & 154.2 \\
\hline \multirow[t]{4}{*}{ Loligo edulis } & Pelagic & 22.5 & 262.5 \\
\hline & & 21.3 & 255.4 \\
\hline & & 20.6 & 241.3 \\
\hline & & 20.4 & 236.6 \\
\hline \multirow[t]{4}{*}{ Watasenia scintillans } & Pelagic & 3.6 & 2.4 \\
\hline & & 3.3 & 2.3 \\
\hline & & 3.3 & 2.3 \\
\hline & & 3.1 & 2.2 \\
\hline \multirow[t]{4}{*}{ Sepia lycidas } & Benthic & 22.1 & 822.1 \\
\hline & & 20.8 & 754.5 \\
\hline & & 20.5 & 744.4 \\
\hline & & 18.2 & 671.3 \\
\hline \multirow[t]{4}{*}{ Euprymna morsei } & Benthic & 2.5 & 7.2 \\
\hline & & 2.3 & 6.3 \\
\hline & & 2.2 & 5.0 \\
\hline & & 2.2 & 5.0 \\
\hline
\end{tabular}

*Mantle length.

tine lay forward on the ventral side of the digestive gland.

Evident differences among species were observed in the shape of the digestive gland. In T. pacificus, the digestive gland was oval and a single. L. bleekeri possessed a single withered-shaped digestive gland. A Well-developed cecal sac was found with cecum in L. bleekeri. Digestive duct's appendages were not well developed in L. bleekeri. The digestive organs of $L$. edulis resembled those of L. bleekeri. The digestive gland was single and withered-shape. A large cecal sac was observed in L. edulis. L. edulis also possessed small digestive ducts' appendages. W. scintillans had an oval digestive gland. Digestive duct's appendages that were not well developed were observed between the cecum and digestive gland. S. lycidas had paired large digestive gland. Developed digestive duct's appendages were shown in $S$. lycidas. Paired bean-like digestive glands were observed in E. morsei. E. morsei also possessed large well-developed digestive duct's appendages.

Weight ratios: The ratios of each digestive organ to body weight are presented in Table 2 and Fig. 2. Considerable variations were observed in the weight ratios of the digestive organs of these species. Though no significant differences were found, there was a weak tendency for the stomach to be larger in benthic species than in pelagic species. Significant differences were found between L. edulis and S. lycidas and between L.edulis and E. morsei species in weight ratio of the stomach. The weight ratio of the stomach was lower in L. edulis $(0.33 \%)$, and it was significantly smaller than that of benthic species $(P<0.05)$. In contrast, weight ratios of the 
(A)

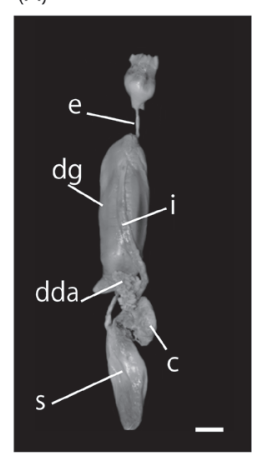

(D)

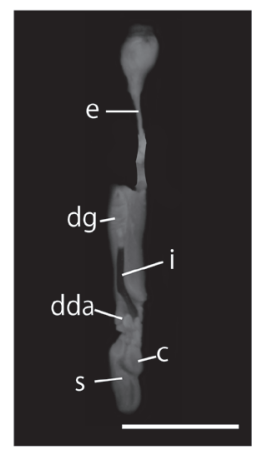

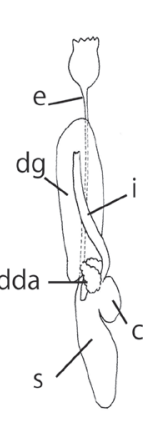

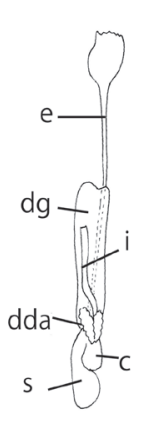

(B)
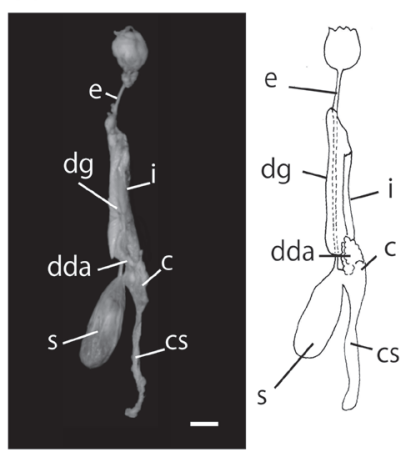

(E)

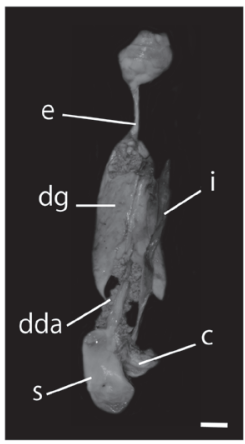

(C)
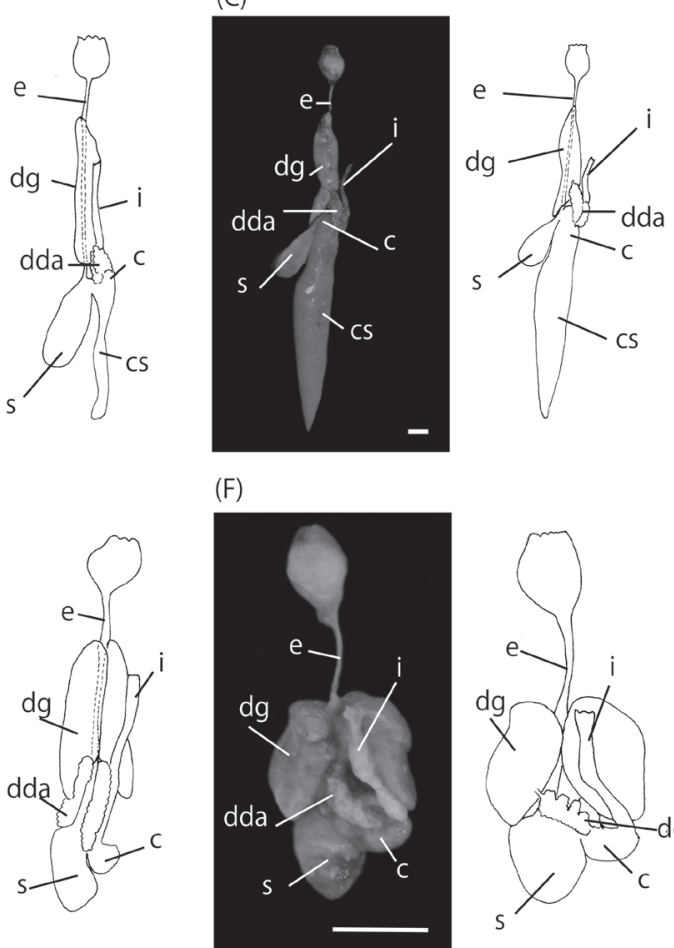

(F)

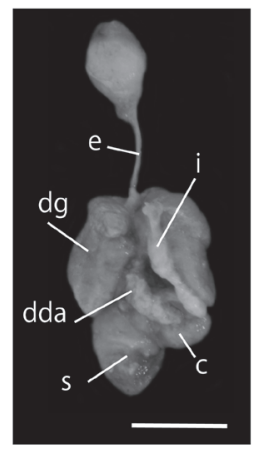

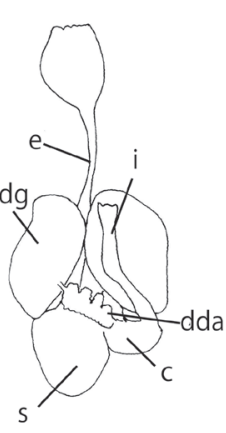

Fig. 1. Ventral view of digestive organs of (A) Todarodes pacificus, (B) Loligo bleekeri, (C) Loligo edulis, (D) Watasenia scintillans, (E) Sepia lycidas and (F) Euprymna morsei. e, esophagus; s, stomach; c, cecum; cs, cecal sac; dg, digestive gland; dda, digestive ducts' appendages; i, intestine. Scale bar $=1 \mathrm{~cm}$.

Table 2. Digestive organ weight ratios (\%)

\begin{tabular}{lcccccccc}
\hline \multicolumn{1}{c}{ Species } & Stomach & & Cecum & & \multicolumn{2}{c}{ Digestive gland } & Digestive ducts' appendages \\
\hline Todarodes pacificus & $0.42 \pm 0.04$ & a & $0.82 \pm 0.06$ & a & $4.98 \pm 0.33$ & a & $0.34 \pm 0.06$ & $\mathrm{a}$ \\
Loligo bleekeri & $0.39 \pm 0.05$ & a & $1.14 \pm 0.18$ & b & $2.25 \pm 0.26$ & $\mathrm{~b}$ & $0.26 \pm 0.04$ & $\mathrm{a}$ \\
Loligo edulis & $0.33 \pm 0.06$ & ab & $0.96 \pm 0.07$ & a & $1.06 \pm 0.11$ & $\mathrm{c}$ & $0.26 \pm 0.05$ & $\mathrm{a}$ \\
Watasenia scintillans & $0.46 \pm 0.03$ & $\mathrm{a}$ & $0.58 \pm 0.03$ & $\mathrm{c}$ & $2.71 \pm 0.30$ & $\mathrm{~d}$ & $0.33 \pm 0.05$ & $\mathrm{a}$ \\
Sepia lycidas & $0.54 \pm 0.12$ & $\mathrm{ac}$ & $0.35 \pm 0.04$ & $\mathrm{~d}$ & $6.04 \pm 0.12$ & $\mathrm{e}$ & $0.56 \pm 0.07$ & $\mathrm{~b}$ \\
Euprymna morsei & $0.51 \pm 0.05$ & $\mathrm{ac}$ & $0.56 \pm 0.04$ & $\mathrm{c}$ & $7.03 \pm 0.42$ & $\mathrm{f}$ & $0.52 \pm 0.08$ & $\mathrm{~b}$ \\
\hline
\end{tabular}

Values are shown as the mean \pm SEM. Different superscript letters indicate significant differences (Holm method) $(P<0.05)$.

stomach for S. lycidas and E. morsei were more than $0.51 \%$. For T. pacificus, L. bleekeri and W. scintillans, the weight ratios of the stomach were less than $0.46 \%$. For pelagic species, the cecum represented larger percentages of body weight than in the benthic species, and there were significant interspecific differences. In $S$. lycidas, the weight ratio of the cecum was $0.35 \%$, and this value was significantly smaller than those of the other species. Significant differences were exhibited among species in weight ratio of the digestive gland. Pelagic species were equipped with smaller digestive glands. The weight ratio of the digestive gland was significantly larger in S. lycidas and E. morsei than in the other species, which had weight ratios of less than $4.98 \%$. Significant differences were observed among species in weight ratio of the digestive duct's appendages. The weight ratios of the digestive duct's appendages of pelagic species were significantly smaller than those of benthic species. Pelagic species showed weight ratios of less than $0.34 \%$ for the digestive ducts' appendages, while benthic species had weight ratios of more than $0.52 \%$.

\section{DISCUSSION}

A comparison of digestive organs showed interspecific variations in shape (Fig. 1) and weight ratios (Fig. 2, Tables 2 and 3). A weak tendency for the stomach to be larger in benthic species than in pelagic species was found in this study (Fig. 2). Mangold and Young [16] mentioned that variations of size and shape of the stomach exist but are often due to the degree of fullness. In this study, the weight ratios of "empty" stomachs showed variations among species. No enzyme secretion occurs in the esophagus and stomach epithelia [4]. 
Table 3. Morphological trend models of digestive organs weight ratios

\begin{tabular}{lcc}
\hline \multicolumn{1}{c}{ Digestive organs } & Pelagic & Benthic \\
\hline Stomach & Small & Large \\
Cecum & Large & Small \\
Digestive gland & Small & Large \\
Digestive ducts' appendages & Small & Large \\
\hline
\end{tabular}

In contrast, a previous study showed that the functions of the stomach are mechanical and enzymatic breakdown of food [16]. Since the stomach is a fleshy muscular organ [16], mechanical breakdown of food may be conducted by movement of the wall of the stomach. Though significant differences were not found between pelagic and benthic species, the weak differences found may be due to the following reasons. Since digestion lasts longer in benthic species than in pelagic species [4], the structure of the stomach of decapodiform cephalopods may be related to digestion time. It has been suggested that highly active swimmers feed more or less continuously or at least several times a day [16]. Since pelagic species always need to swim, they may be able to increase the speed of digestion by holding less food in the stomach and passing quickly through absorptive organs, including the cecum. In contrast, benthic species may accumulate more food in the stomach and pass digestive food to cecum at a slow speed. Since they take advantage of their ability to store food in their larger stomachs, they can digest more food not only while swimming but also burrowing in the sand. This is likely why pelagic species possessed smaller stomachs and benthic species possessed larger stomachs.

The cecum was larger in the pelagic species than in the benthic species in this study (Fig. 2). A large cecal sac was also observed in L. bleekeri and L. edulis (Fig. 1). Our observations support the results of the previous studies by Mangold and Young [16] and Garri and Edith Ré [12] describing a large cecal sac in Loliginidae. The cecum produces enzymes, absorbs nutrients and eliminates indigestible particles, and the cecal sac stores nutrients at later stages of digestion [16]. The main absorptive organ in the cephalopod has long been considered to be the cecum [4], and the large cecal sac and intestine are thought to be the main organs of absorption in the Loliginidae $[1,2]$. The pelagic species may absorb nutrients from their stomachs via their larger cecum, and their larger cecum may enable them to digest food rapidly, particularly in the cecal sac in the case of L. bleekeri and $L$. edulis. Among pelagic species, the size of cecum showed differences. L. edulis and L. bleekeri live along the coasts, and T. pacificus lives along coasts and in offings, and $W$. scintillans lives in the mesopelagic zone. There may be more food along coasts than in offing and the mesopelagic zone. If there is an abundance of food, cephalopods may develop a large cecum for rapid digestion of food. Therefore, $T$. pacificus and $W$. scintillans may require more time for digestion than the other 2 pelagic species. Futhermore, $W$. scintillans may require more time for digestion than other pelagic species, since the mesopelagic zone may contain less food
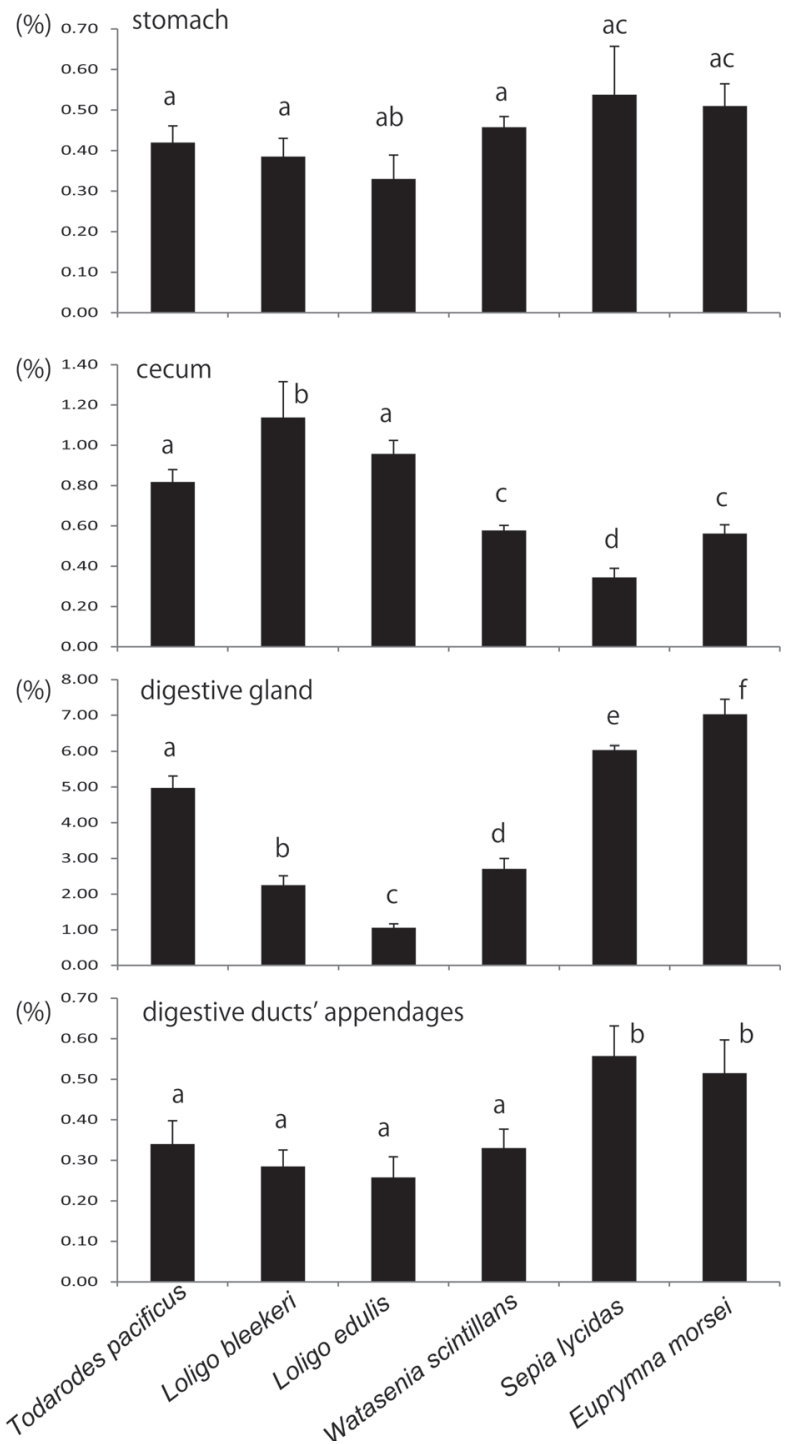

Fig. 2. Digestive organ weight ratios. Different superscript letters indicate significant differences (Holm method, $P<0.05$ ).

than coasts. The relative sizes of the cecum of $W$. scintillans and $E$. morsei were nearly the same. Since benthic species can spend more time on digestion than pelagic species, their cecum may not need to be as large as those in the pelagic species. Therefore, pelagic species had larger cecum than in benthic species.

In this study, the digestive gland was larger in benthic species than in pelagic species (Fig. 2). In particular, L. bleekeri and $L$. edulis possessed a withered-shape digestive gland (Fig. 1). Pelagic species possessed a single digestive gland; in contrast, benthic species had paired glands (Fig. 1). The digestive gland acts as an important digestive and synthetic organ $[4,6]$. It is also considered a storage organ because of its high lipid content $[5,7,15]$. Furthermore, in Sepia, the digestive gland is suggested to be the main absorptive organ [3]. Regarding other functions, the digestive gland of Sepia 
officinalis is thought to be an important storage organ during short-term starvation, but not long-term starvation [8]. Fluckiger et al. [11] showed that the digestive gland may not be a long-term storage organ for dietary lipids, but instead rapidly turns over and potentially excretes lipids in Sepia officinalis. Swift et al. [20] suggested that the major roles of the digestive gland are secretion of digestive enzymes and excretion of metabolic wastes. Lipids are suggested to be excreted from the digestive gland in two tropical loliginids species [19]. In Loligo, it has been suggested that food does not reach the digestive gland [2]. Since L. bleekeri and L. edulis possessed a withered-shape digestive gland in this study, the digestive glands of these 2 loliginids may not store many lipids but instead excrete lipids. It has also been suggested that pelagic species have a single smaller digestive gland to decrease body weight and that excretion of lipids may occur in the digestive gland to enable faster swimming. Among pelagic species, the sizes of the digestive glands were different. Since coasts may contain more food than offing and the mesopelagic zone, $L$. edulis and L. bleekeri do not need to not store a large amount of lipids in the digestive gland. T. pacificus and W. scintillans may absorb nutrients and store lipids in the digestive gland in environments with less food available than along coasts. This is likely why L. edulis and L. bleekeri had smaller digestive glands than T. pacificus and W. scintillans.

In contrast, benthic species have larger paired digestive glands, since they may absorb nutrients and store and excrete lipids effectively. Since pelagic species need to swim and drift more actively than benthic species, a lighter and smaller digestive gland may be suitable for swimming and drifting. This is likely why benthic species had larger digestive gland than pelagic species.

The digestive ducts' appendages were larger and more developed in the benthic species than in the pelagic species (Figs. 1 and 2). In Sepia, the digestive ducts' appendages have a role in absorption of nutrient [3]. The function of the digestive ducts' appendages in the other species of decapodiform cephalopods has not been clarified. Since the pelagic species may absorb nutrients in their larger cecum for rapid digestion, it is possible that the digestive ducts' appendages are not developed. On the other hand, it is also possible that benthic species possess larger digestive duct's appendages because they absorb nutrient via them, in addition to the cecum, more slowly than pelagic species.

This study outlined interspecific variations of the digestive organs of the decapodiform cephalopods. The morphology of the digestive organs of decapodiform cephalopods reflects their speed of digestion and main mode of life in different ecological habitats.

ACKNOWLEDGMENTS. We thank Dr. Takenori Sasaki of The University Museum, The University of Tokyo, for lending equipment and giving important comments. We also thank Mr. Shinnosuke Teruya of The University Museum, The University of Tokyo, for providing some specimens. Finally, we thank Mr. Takashi Yoshimine of Microscope Network for providing a microscope adapter for functional analysis.

\section{REFERENCES}

1. Bidder, A. M. 1950. The digestive mechanism of the European squids Loligo forbesi, Alloteuthis media and Alloteuthis subulata. Q. J. Microsc. Sci. 91: 1-44. [Medline]

2. Bidder, A. M. 1966. Feeding and digestion in Cephalopods. In: Physiology of Mollusca, vol.2 (Wilbur, K. M. and Young, C. M. eds.), Academic Press, New York and London.

3. Boucaud-Camou, E. and Péquignat, E. 1973. Etude experimentale de l'absorption digestive shez Sepia officinalis. L. Forma and Function 6: 93-112.

4. Boucaud-Camou, E. and Boucher-Rodoni, R. 1983. Feeding and digestion in cephalopods. In: The Mollusca, vol.5 (Saleddin, A. S. M. and Wilbur, K. M. eds.), Academic Press, London.

5. Boucaud-Camou, E. and Yim, M. 1980. Fine structure and the function of the digestive cell of Sepia officinalis (Mollusca: Cephalopoda). J. Zool. 191: 89-105. [CrossRef]

6. Boucher-Rodoni, R. 1982. Etude cytologique de la glande digestive de deux céphalopods Eledone cirrosa et Sepia officinalis. Cah. Biol. Mar. 23: 393-413.

7. Boucher-Rodoni, R., Boucaud-Camou, E. and Mangold, K. 1987. Feeding and digestion. In: Cephalopods Life Cycles (Boyle, P. R. ed.), Academic Press, London.

8. Castro, B. G., Garrido, J. L. and Sotelo, C. G. 1992. Changes in composition of digestive gland and mantle muscle of cuttlefish Sepia officinalis during starvation. Mar. Biol. 114: 11-20.

9. Castro, B. G. and Guerra, A. 1990. The diet of Sepia officinalis (Linnaes, 1758) and Sepia elegans Blainville, 1827 (Cephalopoda, Sepioidea) from the Ria de Vigo (NW Spain). Sci. Mar. 54: 375-388.

10. Enriques, P. 1902. Il fegato dei Mollusci e le sue funzioni. Richerche prevalentemente microscopiche. Mitt. Zool. Stn. Neapel. 15: 281-406.

11. Fluckiger, M., Jackson, G. D., Nichols, P., Virtue, P., Daw, A. and Wotherspoon, S. 2008. An experimental study of the effect of diet on the fatty acid profiles of the European Cuttlefish (Sepia officinalis). Mar. Biol. 154: 363-372. [CrossRef]

12. Garri, R. and Egith Ré, M. 2002. Morphología del aparato digestive de Enteroctopus megalocyathus y Loligo sanpaulensis (Mollusca, cephalopoda). Iheringia. Sér. Zool. Porto. Alrgre 92: 81-91.

13. Guerra, A. 2006. Ecology of Sepia officinalis. Vie Milieu 56: 97-107.

14. Hanlon, R. T. and Messenger, J. B. 2008. Cephalopod Behavior. Cambridge University Press, New York.

15. Mangold, K. 1983. Food, feeding habits and growth in some cephalopods. Mem. Natl. Mus. Vic 44: 81-83.

16. Mangold, K. M. and Young, R. E. 1998. The systematic value of the digestive organs. In: Systematics and Biogeography of Cephalopods (Voss, N. A., Vecchione, M., Toll, R. B., and Sweeney, M. J. eds.). Smithson. Contrib. Zool. 586: 21-30.

17. Neves, A., Sequeria, V., Vieira, A. R., Paiva, R. and Gordo, L. S. 2009. Feeding habits of the cuttlefish Sepia officinalis during its lifecycle in the Sado estuary (Portugal). Hydrobiologia 636: 479-488. [CrossRef]

18. Nixson, M. and Young, J. Z. 2003. The Brains and Lives of Cephalopods. Oxford University Press, Oxford.

19. Semmens, J. M. 1998. An examination of the role of the digestive gland of two loliginid squids, with respect to lipid:storage or excretion? Proc. Biol. Sci. 265: 1685-1690. [CrossRef]

20. Swift, K., Johnston, D. and Moltschaniwzkyj, N. 2005. The digestive gland of the southern dumplijng squid (Euprymna tamanica): structure and function. J. Exp. Mar. Biol. Ecol. 315: 177-186. [CrossRef]

21. Voss, N. A. and Voss, R. S. 1983. Phylogenetic relationships in the cephalopod family cranchiidae (oegopsida). Malacol. 23: 397-426. 